\title{
Coronary atheroma [14 cm] extracted from the right coronary artery during off-pump coronary artery bypass grafting
}

\author{
Redoy Ranjan, Dipannita Adhikary, Heemel Saha, Sanjoy Kumar Saha, Kamrul Hasan and \\ Asit Baran Adhikary
}

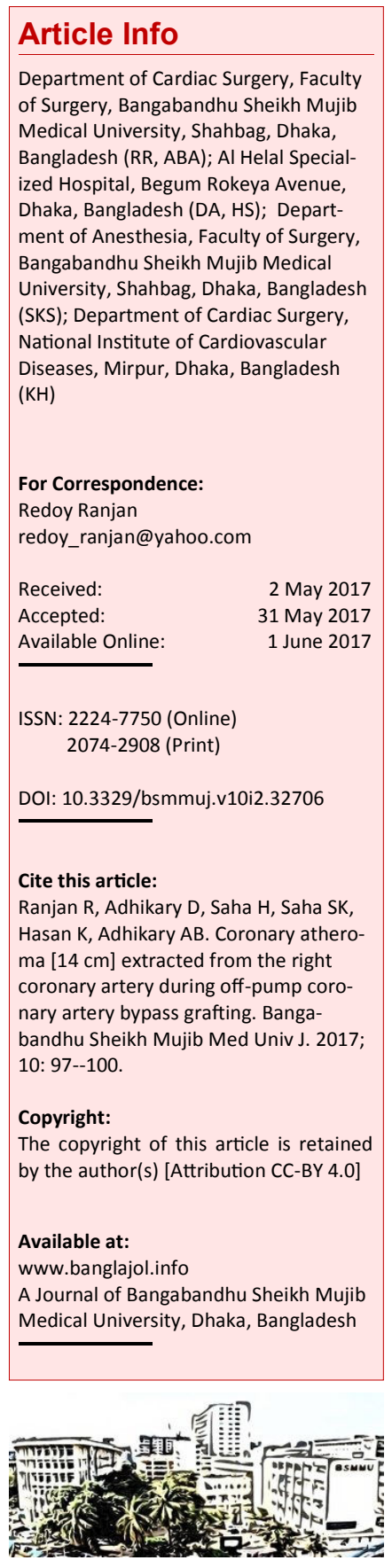

\section{Abstract}

Coronary endarterectomy is a good option for surgical revascularization in diffusely coronary artery disease. In coronary artery bypass surgery, a diffusely diseased right coronary artery is an obstruction to accomplishing complete myocardial revascularization, subsequently increasing the likelihood of a poor postoperative prognosis. Here, we report a case of extraction of a long segment coronary atheroma $(14 \mathrm{~cm})$ from right coronary artery during off-pump coronary artery bypass grafting using closed endarterectomy technique followed by reconstruction with saphenous venous graft.

\section{Introduction}

Coronary endarterectomy was first described in 1957 as a treatment strategy for the coronary artery disease without doing coronary artery bypass graft surgery (CABG).1,2 Coronary endarterectomy is the expulsion of the atheromatous plaque, and isolating the outer media and adventitia layers of the artery and reestablishing the blood flow to the distal part of to the coronary artery. Total revascularization of coronary artery is the basic principle for postoperative outcomes following CABG. However, a large portion of this patients have experienced previous coronary angioplasty. $\frac{3}{3}$ Now-a-days, referred patients for CABG frequently have diffuse and calcified coronary artery disease, which has made complete surgical revascularization of myocardium more difficult and more complicated postoperative recovery. $\frac{3,4}{4}$ Nonetheless, up to $25 \%$ of patients with diffuse coronary artery disease cannot be treated viably and safely by conventional CABG and bringing it as incomplete myocardial revascularization.., 5

The endarterectomy procedure is as yet a matter of controversy. $\frac{6,7}{6}$ There are a few articles revealing concurrent coronary endarterectomy with off-pump CABG surgery. Off-pump CABG surgery for multi vessel myocardial revascularization in high risk patients has been appeared to decrease the frequency of perioperative morbidity and mor-tality and the duration of hospital stay. $\frac{8,9}{}$ Nevertheless, its adverse outcome with mortality and morbidity overshadowed its results in relief of angina. Hence, indications of coronary endarterectomy were limited to patients with diffuse coronary artery disease. 10 Here, we report a case of myocardial revascularization with long segment coronary endarterectomy with CABG of a diffusely disease right coronary artery.

\section{Case Report}

A 58 year old male with diabetes mellitus and hypertension was admitted with shortness of breath on exertion. He had a background history of myocardial infarction at one and half months back. Coronary angiogram demonstrated that he had triple vessel disease with diffusely calcified disease in the right coronary artery showing extreme lesion in the proximal and mid part of right coronary artery. Echocardiography (2D-M) showed regional wall motion abnormality and LV dysfunction (ejection fraction $<40 \%$ ).

He experienced off pump CABG through standard median sternotomy incision. The left internal mammary artery and great saphenous vein were harvested and heparin was used to maintain an activated clotting time more than $400 \mathrm{sec}$. Two proximal anastomoses with ascending aorta to reverse saphenous vein graft were done. We utilized mechanical stabilizers, suction type (Octopus 3; Medtronic) and the compression type (Ultima off-pump CABG frame-work; CTS-Guidant), to immobilize the target coronary artery during grafting. 


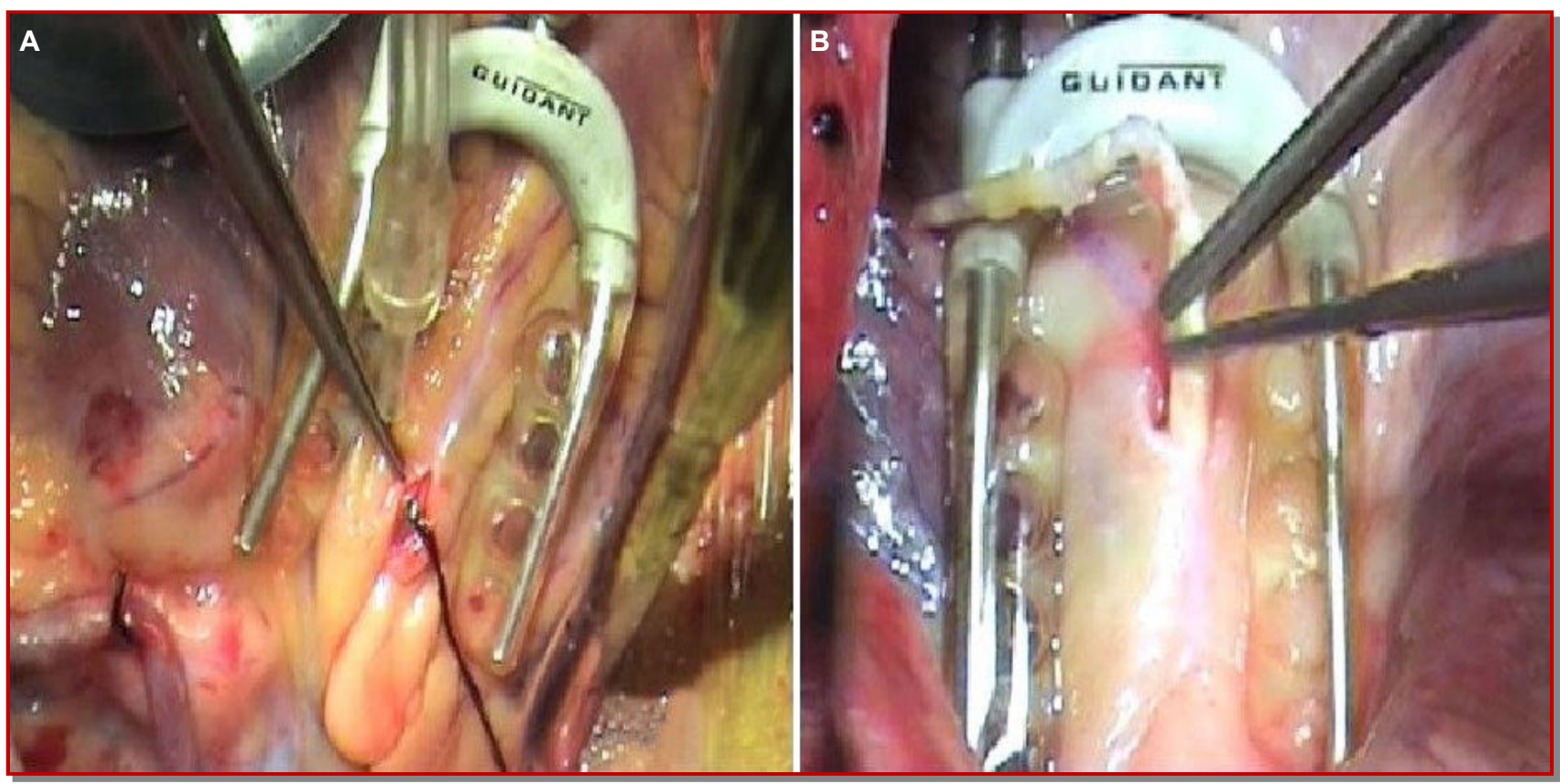

Figure 1: Arteriotomy incision usually 8-10 $\mathrm{mm}$ but may need to extended another $5 \mathrm{~mm}$ in case of diffuse calcified coronary artery disease (A); Extraction of atheromatous plaque by closed technique using ring tip forceps (B)

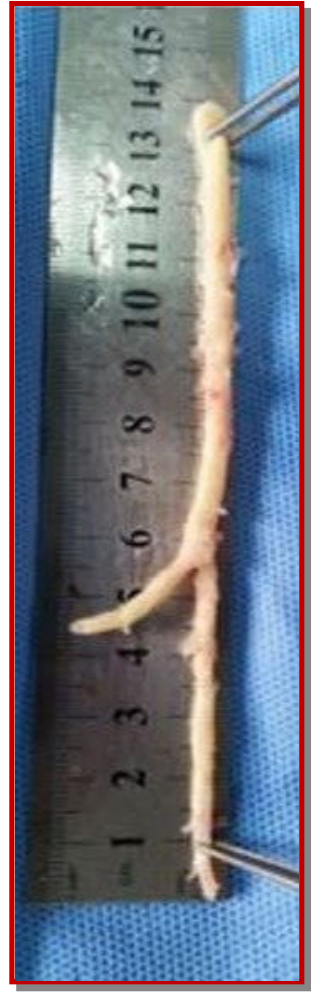

Figure 2: Atheromatous plaque $(14 \mathrm{~cm})$ extraction from the right coronary artery

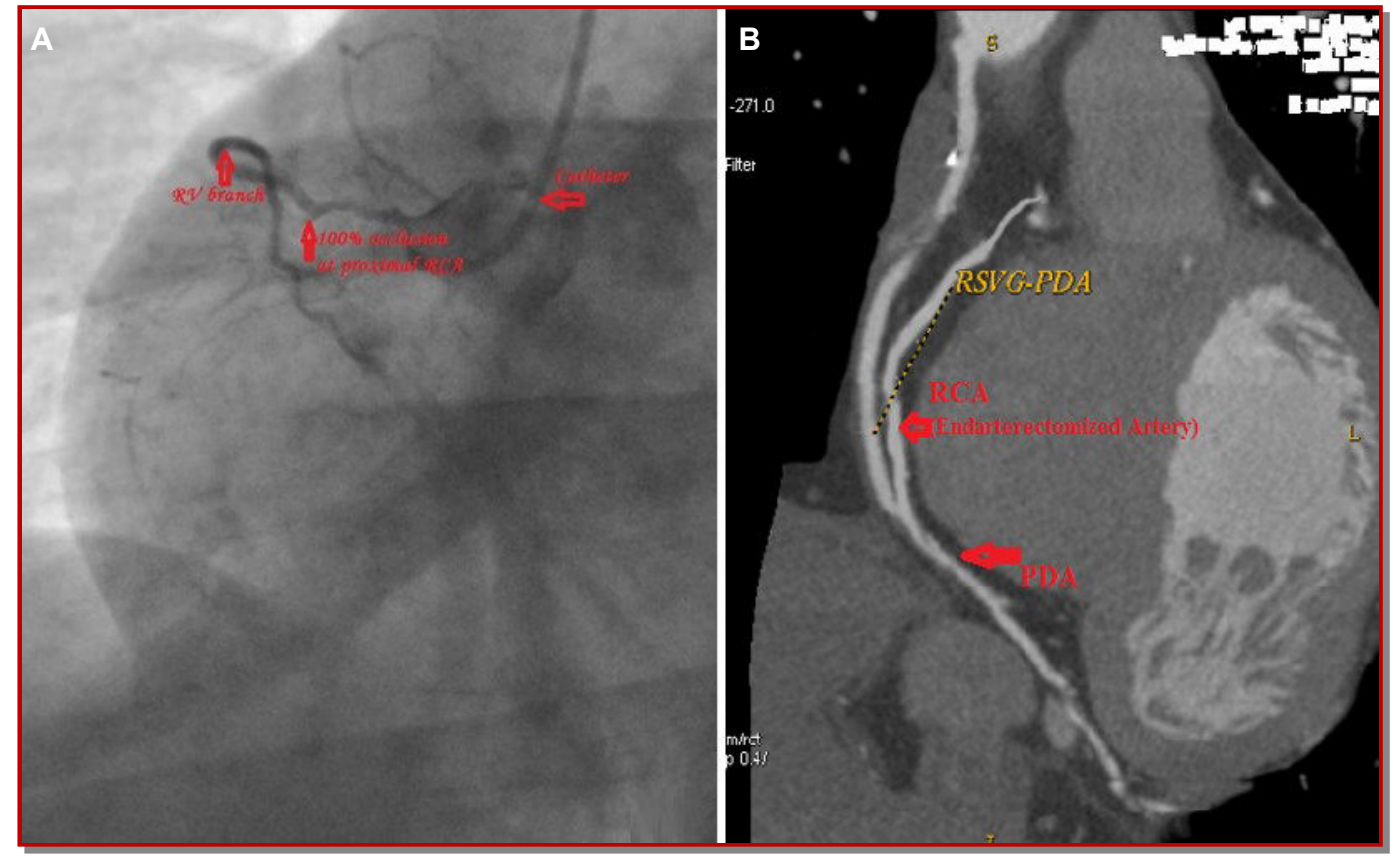

Figure 3: Coronary angiogram before (A) and after surgery (B). Preoperative coronary angiogram shows a total occlusion at proximal part of right coronary artery; Postoperative CT angiogram shows patent right coronary artery and reverse saphenous vein graft to PDA graft

Left coronary artery territory of the heart was revascularized with the left internal mammary artery to the left anterior descending artery graft and reverse saphenous vein graft to obtuse marginal artery (OM) graft. A conclusive decision to endarterectomize right coronary artery was made per-operatively (Figure 1) and a $14 \mathrm{~cm}$ long segment atheroma was extracted (Figure 2) manually through an arteriotomy (10 $\mathrm{mm}$ incision), by slow sustain and continuous traction of atheromatous plaque with the aid of ring forceps, utilizing the closed methods, trailed by reproduction of anastomosis with pre-planned graft using reverse saphenous vein graft. To ensure the complete expulsion of the distal atheroma, the atheromatous plaque carefully inspected for a smooth distal 
tapper end. In addition, back flow of blood from the distal vessel following extraction of the atheroma is a consoling indication of adequate removal atheromatous plaque and that is special feature in off-pump CABG endarterectomy.

Following coronary endarterectomy, routine heparin infusion was prescribed to prevent thrombosis in graft or native tissue in the early postoperative period followed by oral warfarin for the next 6 months. We also used the combination of clopidogrel and ecosprin to attain the better antithrombotic effect. Heparin was continued until desired warfarin effect achieved that is INR (International normalized ratio) is 2.0 to 2.5 . After 6 months, the use of warfarin was stopped but continued with clopidogrel and ecosprin. At follow-up after 8 months of surgery, patient was free from angina and a postoperative CT angiography was performed which revealed the patent graft of the reverse saphenous vein graft to right coronary artery (Figure 3) and also left internal mammary artery to the left anterior descending artery.

\section{Discussion}

In our case, we do total myocardial revascularization with off-pump CABG (4 graft) using left internal mammary artery and reverse saphenous vein graft. Our graft was left internal mammary artery to left anterior descending artery, reverse saphenous vein graft to $\mathrm{OM}_{1}$ and $\mathrm{OM}_{2}$ (sequential graft) and also reverse saphenous vein graft to PDA following long segment coronary atheroma extracted about $14 \mathrm{~cm}$ in size. Postoperatively, we used heparin infusion bridging to oral warfarin for next 6 months and our targeted INR (International normalized ratio) was 2.0 to 2.5. However, after 6 months, the use of warfarin was stopped but combination of clopidogrel and ecosprin was continued.

Total myocardial revascularization in CABG is the most imperative elements that impact long-term morbidity and mortality. Inadequate myocardial revascularization does not influence the quick death rate but has been appeared to be a standout amongst the most critical components that influences perioperative outcome, ventricular function, early and late mortality. $\underline{1,11}$ These patients have more prominent repeated attach of angina, more awful performance in stress tests and a more noteworthy work absence rate and require a higher number of re-interventions, perhaps the better survival rate of complete CABG patients. $3,11 \mathrm{~A}$ conclusive decision to endarterectomize a vessel is made peroperatively and depends on technical contemplations. Coronary endarterectomy was considered when the artery was totally or almost impeded with severely calcified plaques and long segment stenosis that extends distally. There are two various approaches to perform coronary endarterectomy: open and close method. But till now, it is unclear that which is the perfect procedure of coronary endarterectomy. But there is a common practice between these two strategies to remove atherosclerotic plaque that is an arteriotomy is the basic principle in both methods. $\underline{12}$ In open methods, a longitudinal incision for coronary arteriotomy is performed distal to the atheromatous plaque and extracted the atheroma from vessel, followed by reconstruction of endarterectomized site with on lay patch either with Internal thoracic artery or a saphenous venous patch. $\underline{13,14}$ However, a longitudinally opened saphenous vein can be used to repair the arteriotomy and thereafter the left internal mammary artery can be anastomosed with the vein patch.7,15 Note that, this open method is time consuming but the atheromatous plaque is extracted under direct vision, so the openings of the distal end of the left anterior descending artery and side branches can be checked directly. Perhaps in the close method, coronary endarterectomies were performed manually by slow sustain and continuous traction of atheroma trailed by reproduction with anastomosis with pre-planned graft.15 The close method is shorter in duration and the graft anastomosis is easier than open method. Despite delicate balance of traction force, closed endarterectomy may have associated with intimal flap on distal part of endarterectomized vessel. Accordingly, obstacle of the lumen may happen distally as a result of a dissection or thrombus. $\underline{15-17}$

A search of the published literature regarding long segment atheroma extraction and reconstruction following endarterectomy was done and only one article found in India. 18 In a study in India, Nagre shows extraction of a $10 \mathrm{~cm}$ long segment atheroma from LAD followed by patch reconstruction with LIMA and outcome was good.1 In this manner, to the best of our knowledge, this is the first case in Bangladesh of a diffusely disease RCA that was revascularized with reverse saphenous venous graft after extraction of long segment atheroma $(14 \mathrm{~cm})$.

The significant reasons for poor outcomes following coronary endarterectomy are identified with activating of the coagulation cascade due to lack of vascular endothelium in the early postoperative period and proliferation of myofibrointima in late stage. However, in our study, we have better outcome following coronary endarterectomy due to strict administration with anticoagulation and double antiplatelet treatment ought to be executed after endarterectomy. In spite of the fact that the reconstruction was performed effectively following coronary endarterectomy, additional studies are justified to observe the long-term outcome of this technique. 


\section{Conclusion}

Coronary endarterectomy is attainable and accomplishes surgical revascularization in patients with diffuse coronary artery disease, when there is no other alternative for sufficient revascularization. However, coronary endarterectomy is not an alternative to $C A B G$, but an adjunctive to CABG in treating diffuse calcified coronary artery disease.

\section{References}

1. Bailey $\mathrm{CP}$, May A, Lemmon WM. Survival after coronary endarterectomy in man. JAMA. 1957; 164: 641-46.

2. Fundarò P, DiBiasi P, Santoli C. Coronary endarterectomy combined with vein patchre construction and internal mammaryartery grafting: Experience with 18 patients. Tex Heart Inst J. 1987; 14: 389-94.

3. Lawrie GM, Morris Jr GC, Silvers A, Wagner WF, Baron AE, Beltangady SS, Glaeser DH, Chapman DW. The influence of residual disease after coronary bypass on the 5 year survival rate of 1274 men with coronary artery disease. Circulation 1982; 66: 717-23.

4. Trehan N, Mishra A. Endarterectomy complex coronary reconstructions. In: Ischemic heart disease surgical management. Buxton B, Frazier $\mathrm{OH}$, Westaby S (eds). New York, Mosby, 1999; 221-28.

5. Takanashi S, Fukui T, Miyamoto Y. Coronary endarterectomy in the left anterior descending artery. J Cardiol. 2008; 52: 261-68.

6. Gill IS, Beanlands DS, Boyd WD, Finlay S, Keon WJ. Left anterior descending endarterectomy and internal thoracic artery bypass for diffuse coronary disease. Ann Thorac Surg. 1998; 65: 659-62.

7. Mills NE. Coronary endarterectomy: Surgical techniques for patients with extensive distal atherosclerotic coronary disease. Adv Cardiac Surg. 1998; 10: 197-227.

8. Elbardissi AW, Balaguer JM, Byrne JG, Aranki SA. Surgical therapy for complex coronaryartery disease. Semin Thorac Cardiovasc Surg. 2009; 21: 199-206.

9. Al-Ruzzeh $S$, Nakamura $K$, Athanasiou T, Modine T, George S, Yacoub M, Ilsley C, Amrani M. Does off-pump coronary artery bypass (OPCAB) surgery improve the outcome in high-risk patients? A comparative study of 1398 high-risk patients. Eur J Cardiothorac Surg. 2003; 23: 50-55.

10. Schaff HV, Gersh BJ, Pluth JR, Danielson GK, Orszulak TA, Puga FJ, Piehler JM, Frye RL. Survival and functional status after coronary artery bypass grafting: Results 10 to 12 years after surgery in 500 patients. Circulation 1983; 68: 200-04.

11. Berson AJ, Smith JM, Woods SE, Hasselfeld KA, Hiratzka LF. Off-pump versus on-pump coronary artery bypass surgery: Does the pump influence outcome? J Am Coll Surg. 2004; 199: 102-08.

12. Schmitto JD, Kolat $\mathrm{P}$, Ortmann $\mathrm{P}$, Popov AF, Coskun KO, Friedrich M, Sossalla S, Toischer K, Mokashi SA, Tirilomis T, Baryalei MM, Schoendube FA. Early results of coronary artery by passgrafting with coronary endarterectomy for severe coronary artery disease. J Cardiothorac Surg. 2009; 4: 52.

13. Takahashi M, Gohil S, Tong B, Lento P, Filsoufi F, Reddy RC. Early and mid-term results of off-pump endarterectomy of the left anterior descending artery. Interact Cardiovasc Thorac Surg. 2013; 16: 301-05.

14. Fukui T, Takanashi S, Hosoda Y. Long segmental reconstruction of diffusely diseased left anterior descending coronary artery with left internal thoracic artery with or without endarterectomy. Ann Thorac Surg. 2005; 80: 2098-105.

15. Santini F, Casali G, Lusini M,D' Onofrio A, Barbieri E, Rigatelli G, Franco G, Mazzucco A. Mid-term results after extensive vein patch reconstruction and internal mammary grafting of the diffusely diseased left anterior descending coronary artery. Eur J Cardiothorac Surg. 2002; 21: 1020-25.

16. Shapira N, Lumia FJ, Gottdiener JS, Germon P, Lemole GM. Adjunct end arterectomy of the left anterior descending coronary artery. Ann Thorac Surg. 1988; 46: 289-96.

17. Takanashi S, Fukui T, Miyamoto Y. Coronary endarterectomy in the left anterior descending artery. J Cardiol. 2008; 52: 261-68.

18. Nagre SW. Long segment left anterior descending endarterectomy $[10 \mathrm{~cm}]$ and its reconstruction using left internal thoracic artery. J Cardiovasc Med Cardiol. 2016; 3: 23-25. 